\title{
Why stronger radiation safety measures are essential for the modern workforce. A perspective from EAPCI Women and Women as One
}

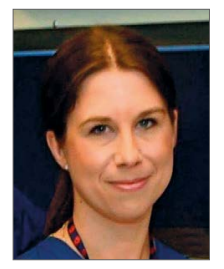

Gill Louise Buchanan ${ }^{1 *}, \mathrm{MD}$; Rebecca Ortega ${ }^{2}, \mathrm{MHA}$; Alaide Chieffo ${ }^{3}, \mathrm{MD}$;

Roxana Mehran, MD; Martine Gilard55, MD; Marie-Claude Morice 6 , MD

\begin{abstract}
1. North Cumbria Integrated Care NHS Foundation Trust, Cumbria, United Kingdom; 2. Women as One Inc., Charlotte, NC, USA; 3. Interventional Cardiology Unit, IRCCS San Raffaele Scientific Institute, Milan, Italy; 4. Icahn School of Medicine at Mount Sinai, New York, NY, USA; 5. Department of Cardiology, Brest University Hospital, Brest, France; 6. Institut Hospitalier Jacques Cartier, Ramsay Générale de Santé, Massy, France
\end{abstract}

G.L. Buchanan and R. Ortega contributed equally to this manuscript.

Interventional cardiology has developed significantly over the last few decades and is often at the cutting edge of new technologies and life-saving procedures. A consequence of this exciting growth is that interventional cardiologists are among the most highly exposed to radiation within the medical field. Concerns over such exposure may deter talented individuals from pursuing such a career regardless of the increased radiation protection and monitoring available in the contemporary era. Women are a particular group who enter interventional cardiology at much lower rates than men. Currently in Europe, women make up a disproportionately low percentage of interventional cardiologists, with representation as low as $5.7 \%$ in countries such as the $\mathrm{UK}^{1}$. Reasons why women choose not to enter the field of interventional cardiology vary, but one reason is that this training often coincides with child-bearing age and interferes with family planning. Unpredictable schedules and long training hours make related choices complex. Radiation exposure during pregnancy introduces an added risk.

A 2019 survey from the European Association of Percutaneous Coronary Interventions (EAPCI) Women Committee reported that $19.6 \%$ of women from the European Society of Cardiology (ESC) database had concerns about radiation exposure ${ }^{2}$.

Article, see page $\mathbf{8 0}$

A 2016 EAPCI Women Committee survey showed that radiation exposure was also an important concern for those considering entering the field. Twice as many women under the age of forty reported that the main reason for not choosing interventional cardiology was due to concerns regarding radiation exposure compared to women over the age of forty ${ }^{3}$. An additional survey from the American College of Cardiology (ACC) and the Society for Cardiovascular Angiography and Interventions (SCAI) indicated that radiation exposure is also one of the top five reasons why women in the USA choose not to enter the field of interventional cardiology ${ }^{4}$. Radiation exposure did not appear among the top five reasons why men choose not to enter the field.

In this edition of EuroIntervention, the results of the 2019 survey from the EAPCI Women Committee are reported from across European cardiac catheterisation laboratories, addressing radiation protection measures and current sex distribution ${ }^{2}$. Despite growing awareness of radiation and perceived concern among all interventional cardiologists, fewer than half of the men and women survey respondents reported wearing a personal dosimeter, with only $8 \%$ being aware of their dose. This may be a reflection that those entering the field are not particularly concerned about radiation protection and hence do not consider monitoring to be important. It is also possible that there is confidence in currently utilised radiation protection measures, which include thyroid shielding and lead glasses. Lack of dosing recognition may also be attributed to a lack of consistency across institutions and countries regarding radiation safety education. Combined, these inconsistencies represent important knowledge and behavioural gaps in the protection of our healthcare workforce.

*Corresponding author: North Cumbria Integrated Care NHS Foundation Trust, Voreda, Portland Place, Penrith, Cumbria, CA11 7QQ, United Kingdom.E-mail: Louise.Buchanan@ncic.nhs.uk 
We must be able to assure those who are currently in the field or who are considering a career in interventional cardiology that proper safety precautions are in place and that we are performing within the appropriate dosing limitations. It is vital that as an interventional cardiology community we recognise radiation protection as a key component of our practice and actively discuss this issue among our teams and across our institutions. As radiation exposure is a stated concern among women who are either already in the field or who are considering entering the field, it is imperative to address the issue of radiation safety specifically among this group, especially women of childbearing age. There should be a mandate for universal and standardised radiation safety education, with stronger data collection and reporting measures in place to support ongoing knowledge and improvements. Not only will these efforts further support our current professionals in the field, but with such increased awareness and standard procedures we may be able to encourage those who would otherwise discount this fantastic career to join the interventional cardiology community.

Women accounted for $18 \%$ of operators in this issue's published survey; however, it must be taken into account that the survey was led by the EAPCI Women Committee, and so results may be an over-representation of the opinions and practices of women compared with the entire interventional cardiology population. Nevertheless, as discussed previously in EuroIntervention ${ }^{1}$, we have an invisible army of women interventional cardiologists whom we need to make visible and who need support. It is important to note that this latest EAPCI Women survey is one step towards uncovering the practices and perceptions of radiation safety among interventional cardiologists in Europe; however, many other organisations are working in similar capacities worldwide. One such organisation is Women as One, a global non-profit organisation founded by Roxana Mehran and MarieClaude Morice in support of women physicians. Women as One has launched with a focus on women in cardiology in general, with a particular interest in issues impacting on women interventional cardiologists.

With recognition that family planning is an essential area of concern for women in cardiology and cardiovascular subspecialities, more effort must be placed on creating family-friendly work environments. For Women as One, this effort includes increasing global dialogue about standardised parental leave and return to work practices and developing instructional tools for both decision makers and practising physicians. Regarding radiation safety, Women as One will produce an instructional guide specifically for pregnant cath lab operators, who too often rely on "word of mouth" recommendations from those who have gone before them.

The efforts of Women as One are focused on working in close collaboration with professional organisations such as the ESC, EAPCI, the ACC and many others in sharing data and best practices, establishing sound policies and promoting women's participation in professional meetings, including roles as live case operators and faculty members. Jointly, the aim is to provide mentorship and ongoing support, including opportunities for women in training to interact with leaders in the field, and by supporting entry into fellowships. Given that women make up a disproportionately low percentage of interventional cardiologists worldwide, collaborating across professional organisations to support growth of a modern workforce becomes essential.

In these extraordinary times, we have seen that to be safe and prepared is imperative and that large-scale change ultimately requires outreach across borders. It also remains imperative to ensure equal access to both information and opportunities, particularly in a field with such high sex-based imbalances. It is therefore vital to create and implement collaborative solutions around radiation safety which keep all interventional healthcare professionals protected and allow our subspecialty to continue its trajectory of breakthrough patient care.

\section{Conflict of interest statement}

A. Chieffo declares that she has received speaker/consultant fees from Abbott, Abiomed, Biosensors, Cardinal Health, and Magenta. R. Mehran declares that she has received grants, personal fees and other from Abbott Laboratories, grants from AstraZeneca, Bayer, Beth Israel Deaconess, CERC, Chiesi, Concept Medical, CSL Behring, DSI, Medtronic, Novartis Pharmaceuticals, and OrbusNeich, grants and other from Bristol-Myers Squibb, other from Abiomed, and The Medicines Company, personal fees from Boston Scientific, Janssen Scientific Affairs, Medscape/WebMD, Roivant Services, Sanofi, and Siemens Medical Solutions, nonfinancial support and other from Idorsia Pharmaceuticals Ltd., and Regeneron Pharmaceuticals, other from Spectranetics/ Philips/Volcano Corp, personal fees from Medtelligence (Janssen Scientific Affairs), other from Watermark Research Partners, Claret Medical, and Elixir Medical, and personal fees from ACC and AMA, outside the submitted work. M.-C. Morice declares that she is the CEO and a shareholder of CERC, a CRO based in Paris. The other authors have no conflicts of interest to declare.

\section{References}

1. Buchanan GL, Mehilli J, Kunadian V, Radu MD, Chieffo A. The invisible army of women in interventional cardiology: EAPCI Women mission to make them visible. EuroIntervention. 2018;14:e1158-9.

2. Manzo-Silberman S, Piccaluga E, Radu MD, James SK, Schüpke S, Vaquerizo B, Kunadian V, Capranzano P, Mehilli J, Buchanan GL, Chieffo A, Mauri J. Radiation protection measures and sex distribution in European interventional catheterisation laboratories. EuroIntervention. 2020;16:80-2.

3. Capranzano P, Kunadian V, Mauri J, Petronio AS, Salvatella N, Appelman Y, Gilard M, Mikhail GW, Schüpke S, Radu MS, Vaquerizo B, Presbitero P, Morice MC, Mehilli J. Motivations for and barriers to choosing an interventional cardiology career path: results from the EAPCI Women Committee worldwide survey. EuroIntervention. 2016;12:53-9.

4. Yong CM, Abnousi F, Rzeszut AK, Douglas PS, Harrington RA, Mehran R, Grines C, Altin SE, Duvernoy CS; American College of Cardiology Women in Cardiology Leadership Council (ACC WIC); Society for Cardiovascular Angiography and Interventions Women in Innovations (SCAI WIN). Sex Differences in the Pursuit of Interventional Cardiology as a Subspecialty Among Cardiovascular Fellows-in-Training. JACC Cardiovasc Interv. 2019;12:219-28 